\title{
Short Sleeping Time and Job Stress in Japanese White-Collar Workers
}

\author{
Naoko Nishitani $^{1,{ }^{*}}$, Hisataka Sakakibara $^{2}$ and Izumi Akiyama ${ }^{3}$ \\ ${ }^{1}$ Sugiyama Jogakuen University, Department of Nursing, 17-3, Hoshigaoka-motomachi, Chikusa-ku, Nagoya 464-8662, \\ Japan \\ ${ }^{2}$ Nagoya University School of Health Sciences, 1-1-20, Daiko-minami, Higashi-ku, Nagoya 461-8673, Japan \\ ${ }^{3}$ Department of Environmental Health Engineering, University of Occupational and Environmental Health, Japan
}

\begin{abstract}
The aim of this study was to clarify the association between sleeping time and job stress in male Japanese workers. Male workers at one manufacturing plant were surveyed about job stress and sleeping time using a selfcompleted questionnaire. A total of 274 white-collar daytime workers were analyzed. Job stress factors and stress response were assessed using the Job Stress Questionnaire. Sleeping time on working days was divided into $\leq 5 \mathrm{~h}, 6 \mathrm{~h}, 7$ $\mathrm{h}$, and $\geq 8 \mathrm{~h}$, and associations between job stress factors and stress response were analyzed. Shorter sleeping time was related to overtime work; about a quarter of those with sleep of $\leq 5 \mathrm{~h}$ worked more than $15 \mathrm{~h}$ overtime per week. Workers with shorter sleeping time, particularly those with $\leq 5 \mathrm{~h}$ sleeping time, were more likely to have job stress factors of quantitative workload and interpersonal conflict as well as psychological stress responses, such as anger, fatigue, tension/anxiety, and depressive symptoms. With shorter sleep, in subjects $\leq 39$ years, scores of activity and fatigue decreased or increased respectively, whereas in those $\geq 40$ years, scores for tension/anxiety and depressive symptoms increased. Shorter sleeping time was related to overtime work and increased job stress in male white-collar workers. Depression symptoms may be more closely associated with shorter sleeping times in workers aged $\geq 40$. Adequate sleep duration is important for maintaining mental health.
\end{abstract}

Keywords: Sleeping time, Job stress, Overtime work, Quantitative workload, Depressive symptoms.

\section{INTRODUCTION}

Approximately 5 to $45 \%$ of daytime Japanese workers are reported to have insomnia, and that number is increasing [1]. Similarly, in the United States, approximately $30 \%$ of workers report insomnia [2]. Survey results in the United States show that the number of people with short sleeping time is increasing, and the proportion of people aged $\geq 18$ years with a short sleeping time $(<6 \mathrm{~h})$ increased from $7.6 \%$ in 1975 to $9.3 \%$ in 2006 [3]. In Japan, sleeping time is also decreasing. According to a 2010 Japan Broadcasting Corporation (NHK) survey in Japanese subjects, the weekday sleeping time of men aged $\geq 40$ years decreased 20 to 40 min between 1995 and 2010. There are various reasons for this decrease in sleeping time, including diversification of work patterns and socioeconomic reasons. In particular, long working hours are said to be related to reduced sleeping time [3]. A shorter sleeping time has various mental and physical effects and is closely related to onset and progression of hypertension, diabetes, and dyslipidemia [49]. Obesity, a leading lifestyle-related disease, is also thought to be associated with short sleeping time [5, 8-15]. Moreover, previous research has shown that as sleeping time shortens, blood levels of C-reactive protein (CRP) and interleukin-6 (IL-6) increase $7 \%$ to $8 \%$ [16].

*Address correspondence to this author at the Sugiyama Jogakuen University, Department of Nursing, 17-3, Hoshigaoka-motomachi, Chikusaku, Nagoya 464-8662, Japan; Tel / Fax: +81-(0)52-781-9268;

E-mail: n-nishitani@sugiyama-u.ac.jp
Job stress is thought to be strongly related to sleep in workers. A previous study of Japanese subjects showed that high job stress was related to short sleeping time, particularly in men [17]. In addition, job stress is reportedly related not only to sleeping time, but may also cause the quality of sleep to decrease $[18,19]$. In particular, interpersonal conflicts, appropriateness of work, and social support have been shown to be related to sleep [20]. Similarly, our previous study [21] suggested that for workers, not getting sufficient sleep decreases work efficiency and may lead to safety problems. An association between short sleeping time and mental and physical symptoms is reported in the general adult population as well [22]. Getting enough sleep is therefore important.

Middle-aged white-collar workers may have high responsibility to manage subordinates and fulfill their duties. Among white-collar males as well, insomnia is reported to be connected with work-related stress responses [20]. However, there are few surveys of the association between sleeping time and job stress in Japanese white-collar workers. Hence, in the present study, we focused on sleeping time and investigated the association between short sleeping time and job stress in Japanese white-collar workers. Moreover, we compared associations between sleep times and job stress by age groups of $\leq 39$ years and $\geq 40$ years, because the 2011 patient survey by the Ministry of Health, Labour and Welfare have shown that the prevalence of depressed patients in males is higher in the age of 40-50's than in the 20-30's. 


\section{METHODS}

\section{Study Subjects}

Subjects were male employees of a manufacturing plant. Self-completed surveys were distributed to all 1,310 men at the time of a health checkup conducted in April and May 2005. The survey forms were collected from 1,118 men (collection rate $85.3 \%$ ) who consented to this survey. After excluding people being treated for or with a history of psychiatric disease, shift workers, and management-level employees, there were 594 daytime workers aged $\leq 60$ years. Of them, after excluding blue-collar workers, the final subjects for the present analysis included 274 white-collar workers, such as engineers and clerical workers (21-60 years old, mean age $41.1 \pm 11.9$ years).

This study was approved by the ethics review board of the Nagoya University School of Medicine.

\section{Contents of Questionnaire Survey}

\section{Basic Attributes and Living Habits}

The survey included items related to age, sex, work pattern (daytime work or shift work), living with other family members or not, type of work (white-collar or blue collar), overtime work (mean hours per week excluding weekend work), walking time during commute, mean sleeping time (mean hours on working days), whether or not the subject exercise regularly and if so the frequency (number of days/week), smoking status (nonsmoker, previous smoker, or smoker), alcohol consumption (mean number of days drinking alcohol per week), and subjective health status (good, somewhat good, somewhat poor, poor).

\section{Job Stress}

The Job Stress Questionnaire (JSQ), which was created in a study commissioned by the Japanese Ministry of Health, Labor and Welfare, was used in the present study [23]. The Questionnaire has been shown to have Cronbach $\alpha$ coefficient of 0.74 for job stress factors, 0.84 for psychological stress response, 0.81 for physical stress response, and 0.83 for support. The questionnaire includes 17 items to measure job stress factors. These are categorized as quantitative workload, qualitative workload, physical workload, job latitude, application of technology, interpersonal conflict, workplace environment, and appropriateness of work. Answers are given on a four-point scale of "agree," "somewhat agree," "somewhat disagree," and "disagree." The burden from stressors is considered to be higher with lower scores for job latitude and appropriateness of work, and with higher scores for all other items. Stress response can be measured as psychological and physical stress responses. The section on psychological stress response had 18 items to measure positive responses (activity) and negative responses (anger, fatigue, tension/anxiety, and depressive symptoms). The section to assess physical stress response had 11 items. The four choices for responses to questions about psychological and physical stress were "almost never," "sometimes," "often," and "almost all the time." Among psychological stress responses, lower scores for activity and higher scores for other items were considered to indicate higher stress responses. Higher total scores for physical stress response were considered to indicate higher stress responses.

With respect to those questions, subjects were asked about sleeping time and psychological and physical stress responses which they experienced in the last one month.

\section{Statistical Analysis}

Sleeping time was divided into $\leq 5 \mathrm{~h}, 6 \mathrm{~h}, 7 \mathrm{~h}$, and $\geq 8 \mathrm{~h}$, and the $\chi^{2}$ test and analysis of variance (ANOVA) were used to test for associations with basic attributes and living habits. ANOVA was used for mean scores for job stress factors and stress response with each sleeping time. Dunnett's test was used to compare shorter sleeping times with sleeping time $\geq$ $8 \mathrm{~h}$. In addition, subjects were divided by age into $\leq 39$ years and $\geq 40$ years, and the mean score for job stress factors and stress response was investigated for each sleeping time by age group. SPSS 17.0 was used for statistical analysis.

\section{RESULTS}

\section{Basic Attributes and Living Habits}

Subjects with decreased sleeping time were significantly younger $(\mathrm{p}<0.01$, Table 1$)$. With shorter sleeping times, there were also significantly more people who worked overtime $(\mathrm{p}<0.001)$, and the mean overtime hours per week significantly increased $(\mathrm{p}<0.01)$. Workers with sleeping time $\leq 5 \mathrm{~h}$ were more likely to work $\geq 15$ overtime hours per week $(p<0.05)$. On the other hand, with longer sleeping times, more workers had a subjective health state of "good" or "somewhat good" $(\mathrm{p}<0.01)$, and consumed alcohol $\geq 5$ days a week $(p<0.001)$. No significant differences were found in body mass index (BMI), smoking habits, and exercise habits among sleeping time groups.

\section{Sleeping Time and Job Stress Factors, Stress Response}

In terms of mean scores for job stress factors for different sleeping times (Table 2), the scores for quantitative workload $(p<0.001)$ and interpersonal conflict $(p<0.05)$ were significantly higher with shorter sleeping times. Compared with the group with $\geq 8 \mathrm{~h}$ sleeping time, scores of quantitative workload were significantly higher in the groups with $\leq 5 \mathrm{~h}, 6 \mathrm{~h}$, and $7 \mathrm{~h}$ sleeping time $(\mathrm{p}<0.001, \mathrm{p}<0.01$, and $\mathrm{p}<0.05$. respectively). The scores for interpersonal conflict were also higher in the group with $\leq 5 \mathrm{~h}$ sleeping time $(\mathrm{p}<0.05)$.

When the association between sleeping time and job stress factors was further investigated with two age groups of $\leq 39$ years and $\geq 40$ years, the scores for quantitative workload was significantly higher with shorter sleeping times in both groups $(\mathrm{p}<0.05)$. No significant differences were found between sleeping times and other job stress factors. Moreover, in the Dunnett's test results, for subjects aged $\geq 40$, scores of quantitative workload were significantly higher in the groups with $\leq 5 \mathrm{~h}$ and $6 \mathrm{~h}$ sleeping time than in the group with $\geq 8 \mathrm{~h}$ sleeping time $(\mathrm{p}<0.05)$. No significant differences were found in subjects aged $\leq 39$.

In terms of stress response (Table 3 ), mean scores for all items other than activity were significantly higher with shorter sleeping times: anger $(p<0.05)$, fatigue $(p<0.001)$, tension/anxiety $(p<0.05)$, depressive symptoms $(p<0.05)$, and 
Table 1. Results for Basic Attributes, Lifestyle, and Health Feeling

\begin{tabular}{|c|c|c|c|c|c|}
\hline \multirow[t]{3}{*}{ Characteristic } & \multicolumn{4}{|c|}{ Sleeping Time } & \multirow[t]{2}{*}{$P$ for Trend } \\
\hline & $\leq \mathbf{5 h}$ & $6 \mathrm{~h}$ & $7 \mathrm{~h}$ & $\geq 8 \mathrm{~h}$ & \\
\hline & $\mathbf{n}=\mathbf{3 7}$ & 119 & 94 & 24 & \\
\hline Age $(\text { year })^{a}$ & $38.2 \pm 10.4$ & $39.8 \pm 11.8$ & $42.8 \pm 12.2$ & $45.0 \pm 12.4$ & 0.005 \\
\hline $\operatorname{BMI}\left(\mathrm{kg} / \mathrm{m}^{2}\right)^{\mathrm{a}}$ & $23.4 \pm 2.8$ & $24.3 \pm 3.0$ & $23.6 \pm 3.1$ & $23.0 \pm 3.4$ & 0.278 \\
\hline Overtime work ${ }^{\mathrm{b}}$ & $31(86.1)$ & $89(77.4)$ & $62(67.4)$ & $9(39.1)$ & $<0.001$ \\
\hline Overtime $(\mathrm{h} / \text { week })^{\mathrm{a}}$ & $9.9 \pm 10.7$ & $7.7 \pm 8.6$ & $5.8 \pm 6.2$ & $2.7 \pm 1.3$ & 0.005 \\
\hline Overtime ( $\geq 15 \mathrm{~h} /$ week $)^{\mathrm{b}}$ & $8(26.7)$ & $12(13.6)$ & $6(10.2)$ & 0 & 0.020 \\
\hline Smoking ${ }^{\mathrm{b}}$ & $15(40.5)$ & $43(36.1)$ & $34(36.2)$ & $16(66.7)$ & 0.151 \\
\hline No exercise ${ }^{b}$ & $27(73.0)$ & $80(67.2)$ & $59(62.8)$ & $12(50.0)$ & 0.062 \\
\hline Alcohol consumed ${ }^{\mathrm{b}}(\geq 5$ days/week $)$ & $9(24.3)$ & $39(32.8)$ & $47(50.0)$ & $14(60.9)$ & $<0.001$ \\
\hline Health feeling ${ }^{\mathrm{b}}$ (good, somewhat good) & $26(70.3)$ & $95(79.8)$ & $81(86.2)$ & $23(95.8)$ & 0.005 \\
\hline
\end{tabular}

${ }^{\mathrm{a}}$ mean $\pm \mathrm{SD},{ }^{\mathrm{b}} \mathrm{n}(\%)$

Table 2. Mean Values for Job Stress Factor for each Sleeping Time

\begin{tabular}{|c|c|c|c|c|c|}
\hline \multirow[t]{3}{*}{ Characteristic } & \multicolumn{4}{|c|}{ Sleeping Time } & \multirow[t]{2}{*}{$P$ for Trend } \\
\hline & $\leq \mathbf{5 h}$ & $6 \mathrm{~h}$ & $7 \mathrm{~h}$ & $\geq 8 \mathrm{~h}$ & \\
\hline & $\mathbf{n}=\mathbf{3 7}$ & 119 & 94 & 24 & \\
\hline Quantitative workload & $9.3 \pm 2.2 * * *$ & $8.7 \pm 2.2 * *$ & $8.4 \pm 2.3 *$ & $7.0 \pm 2.1$ & $<0.001$ \\
\hline Qualitative workload & $8.5 \pm 1.9$ & $8.3 \pm 2.0$ & $8.2 \pm 2.0$ & $7.5 \pm 1.9$ & 0.092 \\
\hline Physical workload & $2.2 \pm 0.9$ & $1.9 \pm 0.8$ & $2.0 \pm 0.9$ & $2.0 \pm 0.9$ & 0.595 \\
\hline Job latitude & $8.6 \pm 1.6$ & $8.4 \pm 1.9$ & $8.8 \pm 2.0$ & $9.3 \pm 2.1$ & 0.063 \\
\hline Application of technology & $2.2 \pm 0.8$ & $2.1 \pm 0.8$ & $2.0 \pm 0.8$ & $2.3 \pm 1.0$ & 0.937 \\
\hline Interpersonal conflict & $6.8 \pm 2.0 *$ & $6.1 \pm 2.0$ & $6.1 \pm 1.8$ & $5.5 \pm 2.2$ & 0.019 \\
\hline Workplace environment & $2.1 \pm 0.9$ & $1.8 \pm 0.8$ & $1.8 \pm 0.8$ & $1.6 \pm 0.8$ & 0.057 \\
\hline Appropriateness of work & $5.7 \pm 1.3$ & $5.5 \pm 1.4$ & $5.6 \pm 1.3$ & $6.0 \pm 1.2$ & 0.353 \\
\hline
\end{tabular}

${ }^{* * *} \mathrm{p}<0.001, * * \mathrm{p}<0.01,{ }^{*} \mathrm{p}<0.05$ by Dunnett's test (compared with sleeping time $\geq 8 \mathrm{~h}$ )

Table 3. Mean Values for Job Stress Response for each Sleeping Time

\begin{tabular}{|c|c|c|c|c|c|}
\hline Job Stress Response & \multicolumn{4}{|c|}{ Sleeping Time } & \multirow[t]{2}{*}{$P$ for Trend } \\
\hline \multirow{2}{*}{ Psychological Stress Response } & $\leq \mathbf{5 h}$ & $6 \mathrm{~h}$ & $7 \mathbf{h}$ & $\geq 8 \mathrm{~h}$ & \\
\hline & $\mathbf{n}=\mathbf{3 7}$ & 119 & 94 & 24 & \\
\hline Activity & $6.5 \pm 2.4$ & $6.5 \pm 2.1$ & $7.1 \pm 2.2$ & $6.6 \pm 2.5$ & 0.204 \\
\hline Anger & $6.5 \pm 2.3$ & $6.1 \pm 2.3$ & $5.8 \pm 2.1$ & $5.3 \pm 2.4$ & 0.027 \\
\hline Fatigue & $6.4 \pm 2.1 * *$ & $5.9 \pm 2.0 * *$ & $5.5 \pm 2.0 *$ & $4.5 \pm 1.7$ & $<0.001$ \\
\hline Tension/Anxiety & $6.4 \pm 1.8 *$ & $5.6 \pm 2.0$ & $5.4 \pm 1.8$ & $5.1 \pm 2.3$ & 0.010 \\
\hline Depressive symptoms & $9.9 \pm 3.6$ & $9.5 \pm 3.4$ & $9.0 \pm 2.8$ & $8.3 \pm 4.0$ & 0.026 \\
\hline Overall & $37.5 \pm 9.5^{*}$ & $35.6 \pm 9.4$ & $33.6 \pm 8.4$ & $31.5 \pm 8.5$ & 0.003 \\
\hline Physical stress response & $18.9 \pm 5.3 *$ & $17.1 \pm 4.8$ & $16.6 \pm 4.2$ & $15.9 \pm 4.9$ & 0.008 \\
\hline
\end{tabular}

${ }^{*}{ }^{*} \mathrm{p}<0.01,{ }^{*} \mathrm{p}<0.05$ by Dunnett's test (compared with sleeping time $\geq 8 \mathrm{~h}$ ) 
Table 4. Mean Values for Job Stress Response for each Sleeping Time ( $\leq 39$ Years, $\geq 40$ Years)

\begin{tabular}{|c|c|c|c|c|c|}
\hline Job Stress Response & \multicolumn{4}{|c|}{ Sleeping Time } & $P$ for Trend \\
\hline & $\mathrm{n}=\mathbf{2 4}$ & 65 & 42 & 8 & \\
\hline Activity & $6.4 \pm 2.8$ & $6.4 \pm 1.8$ & $7.5 \pm 2.2$ & $7.6 \pm 2.3$ & 0.010 \\
\hline Anger & $6.8 \pm 2.3$ & $6.4 \pm 2.3$ & $6.0 \pm 2.4$ & $6.6 \pm 2.5$ & 0.328 \\
\hline Tension/Anxiety & $6.3 \pm 1.8$ & $5.8 \pm 2.1$ & $5.4 \pm 1.9$ & $6.6 \pm 2.6$ & 0.364 \\
\hline Depressive symptoms & $10.2 \pm 3.4$ & $10.0 \pm 3.7$ & $9.1 \pm 3.1$ & $11.0 \pm 6.1$ & 0.571 \\
\hline Overall & $38.9 \pm 9.5$ & $37.5 \pm 9.7$ & $33.7 \pm 9.6$ & $37.6 \pm 12.0$ & 0.087 \\
\hline Physical stress response & $19.5 \pm 5.5$ & $17.4 \pm 4.8$ & $16.3 \pm 4.4$ & $18.3 \pm 6.5$ & 0.061 \\
\hline Fatigue & $5.1 \pm 1.3$ & $5.0 \pm 1.7$ & $5.3 \pm 1.8$ & $3.6 \pm 1.0$ & 0.111 \\
\hline Tension/Anxiety & $6.4 \pm 1.9$ & $5.3 \pm 1.9$ & $5.4 \pm 1.7$ & $4.3 \pm 1.7$ & 0.018 \\
\hline Depressive symptoms & $9.5 \pm 4.0$ & $8.8 \pm 3.0$ & $8.8 \pm 2.7$ & $6.9 \pm 1.1$ & 0.030 \\
\hline Overall & $34.7 \pm 9.2$ & $33.2 \pm 8.5$ & $33.5 \pm 7.3$ & $28.5 \pm 3.9$ & 0.075 \\
\hline Physical stress response & $17.8 \pm 4.9$ & $16.8 \pm 4.8$ & $16.8 \pm 4.1$ & $14.7 \pm 3.6$ & 0.104 \\
\hline
\end{tabular}

total score for psychological stress responses $(p<0.01)$. Total score for physical stress response was also significantly higher with shorter sleeping times $(\mathrm{p}<0.01)$. Compared with the group with $\geq 8 \mathrm{~h}$ sleeping time, the scores of fatigue were significantly higher in the groups with $\leq 5 \mathrm{~h}, 6 \mathrm{~h}$ and $7 \mathrm{~h}$ sleeping time $(\mathrm{p}<0.01, \mathrm{p}<0.01$, and $\mathrm{p}<0.05$. respectively). The scores of tension/anxiety, total scores of psychological stress responses, and physical stress response were respectively significantly higher in the group with $\leq 5 \mathrm{~h}$ sleeping time than in the group with $\geq 8 \mathrm{~h}$ sleeping time $(\mathrm{p}<0.05)$.

In the subjects aged $\leq 39$ (Table 4 ), scores for activity significantly decreased $(p<0.05)$, and those for fatigue significantly increased with shorter sleeping times $(\mathrm{p}<0.05)$. In the subjects aged $\geq 40$, scores for tension/anxiety and depressive symptoms increased significantly $(p<0.05)$.

\section{DISCUSSION}

This study showed that shorter sleeping time was related to overtime work, as well as the job stress factors of quantitative workload and interpersonal conflict. Furthermore, psychological stress responses, such as anger, fatigue, tension/anxiety, and depressive symptoms were shown to increase with shorter sleeping time, particularly in subjects who slept $\leq 5 \mathrm{~h}$ per day. In addition, in subjects aged $\leq 39$, the scores of activity and fatigue decreased or increased, respectively, whereas in subjects aged $\geq 40$, the scores for tension/anxiety and depressive symptoms increased. Shorter sleep duration was more closely associated with depressive symptoms in workers aged $\geq 40$.
Long working hours may lead to shorter sleeping times [3]. Working for $\geq 11 \mathrm{~h}$ per day, or $55 \mathrm{~h}$ per week, can reportedly increase the risk of having sleeping time of $<7 \mathrm{~h}$ per day nearly two times compared with people who work 35 to $40 \mathrm{~h}$ per week [24]. In the present study, about one quarter of people with sleeping times $\leq 5 \mathrm{~h}$ worked more than $15 \mathrm{~h}$ of overtime per week. Overtime work of $>15 \mathrm{~h}$ per week could be equivalent to working $\geq 11 \mathrm{~h}$ per day in the case of a 5day week, which might increase the risk of acute heart disease [25]. In addition, overtime work was also associated with a greater quantitative workload of job stress factors, which might also contribute to a decrease in sleeping time. These findings were in accordance with an earlier study showing an association between high job stress factors and short sleeping time [17].

As shown in Table $\mathbf{3}$, mean scores for job stress responses of anger, fatigue, tension/anxiety, depressive symptoms and physical stress response increased with shorter sleeping time. Depression scores have been shown to be related to long working hours and short sleeping time [26]. The risk of depression was about 1.73 times greater in people working $>10 \mathrm{~h}$ per day than for those working 6 to 8 $\mathrm{h}$ per day. Similarly the risk was 1.62 times higher in persons who slept $<6 \mathrm{~h}$ than in those who slept 7 to $8 \mathrm{~h}$. The combined risk for depression was 2.69 times greater in persons working $>10 \mathrm{~h}$ who slept $<6 \mathrm{~h}$, compared with those working 6 to $8 \mathrm{~h}$ who slept $>6 \mathrm{~h}$. Moreover, a previous study of Japanese people reported that 19 of 22 people who committed suicide had worked $\geq 11 \mathrm{~h}$ per day and were also depressed [27]. In the present results, shorter sleeping time 
was associated with long working hours and depressive symptoms together with anger, fatigue, tension/anxiety and physical stress response. The Subjective sense of well-being was also lower in persons with shorter sleeping times. Thus, short sleeping time can be associated with both physical and mental health, including an increased risk of depressive symptoms and a decreased sense of well-being [28].

The present study also showed that there were age differences in the stress responses associated with shorter sleeping time. With shorter sleeping time, the scores for tension/anxiety and depressive symptoms increased in people aged $\geq 40$ years. On the other hand, in persons aged $\leq$ 39 years, significant trends were found in activity and fatigue, but not depression. These findings suggest that short sleep duration may be more closely associated with depressive symptoms among middle-aged workers. This might be presumed to be associated with a decline in physical and mental function and greater job demands including management tasks in middle-aged workers, or other factors. The 2011 patient survey by the Ministry of Health, Labor and Welfare reported that the prevalence of males with mood disorders that are mainly constituted by depression is the highest in men in their 40's. It may be necessary for middle-aged male workers to be more careful about depressive symptoms and mental health as well as adequate sleep duration.

In this study, mean sleeping time was $6.5 \pm 1.0 \mathrm{~h}$ for people aged $\geq 40$ versus $6.2 \pm 0.9 \mathrm{~h}$ for those aged $\leq 39$. It was shorter in the younger generation. Similar results were shown in a previous study [29]. Sleeping time of younger workers may be influenced by factors other than work such as.

There were some limitations of this study. First, the present study was a cross-sectional study using a selfcompleted questionnaire. Hence, this study cannot show a causal relationship. Second, we focused on sleeping time and job stress. Assessing quality of sleep as well as sleeping time is important in the evaluation of sleep. However, we did not examine sleep quality in this study. Third, we did not inquire about daytime sleepiness, caffeine intake, or other xanthine beverages, which might affect sleep. With regard to medication, respondents with psychiatric disorders under treatment were excluded in the present analyses. Fourth, depressive symptoms were assessed using JSQ of selfreported questionnaire surveys, which was not a questionnaire specific for depression. Our study may be indicative of depressive symptoms milder than clinical depression. Lastly, study subjects were male white-collar workers at a single manufacturing plant, excluding management level workers. Further studies will be needed with larger numbers of people in other types of work, shift workers, women, and persons in other areas of business.

\section{CONCLUSION}

This study showed that shorter sleeping time on working days was related to overtime work and increased quantitative workload in male white-collar workers. Shorter sleep duration was more closely associated with depressive symptoms and tension/anxiety in workers $\geq 40$ and activity and fatigue in those $<40$ years. It may be necessary for middle-aged male workers to be more careful about depressive symptoms as well as sleeping an adequate number of hours per night.

\section{CONFLICTS OF INTEREST}

The authors confirm that this article content has no conflicts of interest.

\section{ACKNOWLEDGEMENTS}

Declared none.

\section{REFERENCES}

[1] Doi Y. An epidemiologic review on occupational sleep research among Japanese workers. Ind Health 2005; 43: 3-10.

[2] Kuppermann M, Lubeck DP, Mazonson PD, et al. Sleep problems and their correlates in a working population. J Gen Intern Med 1995; 10: 25-32.

[3] Knutson KL, Van Cauter E, Rathouz PJ, Deleire T, Lauderdale DS. Trends in the prevalence of short sleepers in the USA: 1975-2006. Sleep 2010; 33: 37-45

[4] Gottlieb DJ, Redline S, Nieto FJ, et al. Association of usual sleep duration with hypertension: the Sleep Heart Health Study. Sleep 2006; 29: 1009-14.

[5] Knutson KL, Van Cauter E. Associations between sleep loss and increased risk of obesity and diabetes. Ann N Y Acad Sci 2008; 1129: 287-304.

[6] Kaneita Y, Uchiyama M, Yoshiike N, Ohida T. Associations of usual sleep duration with serum lipid and lipoprotein levels. Sleep 2008; 31: 645-52.

[7] Hall MH, Muldoon MF, Jennings JR, Buysse DJ, Flory JD, Manuck SB. Self-reported sleep duration is associated with the metabolic syndrome in midlife adults. Sleep 2008; 31: 635-43.

[8] Singh M, Drake CL, Roehrs T, Hudgel DW, Roth T. The association between obesity and short sleep duration: a populationbased study. J Clin Sleep Med 2005; 1: 357-63.

[9] Bjorvatn B, Sagen IM, Ǿyane N, et al. The association between sleep duration, body mass index and metabolic measures in the Hordaland Health Study. J Sleep Res 2007; 16: 66-76.

[10] Patel SR, Hu FB. Short sleep duration and weight gain: a systematic review. Obesity 2008; 16: 643-53.

[11] Kohatsu ND, Tsai R, Young T, et al. Sleep duration and body mass index in a rural population. Arch Intern Med 2006; 166: 1701-05.

[12] Moreno CR, Louzada FM, Teixeira LR, Borges F, Lorenzi-Filho G. Short sleep is associated with obesity among truck drivers. Chronobiol Int 2006; 23: 1295-303.

[13] Ko GT, Chan JC, Chan AW, et al. Association between sleeping hours, working hours and obesity in Hong Kong Chinese: the 'better health for better Hong Kong' health promotion campaign. Int J Obes 2007; 31: 254-60.

[14] Lauderdale DS, Knutson KL, Yan LL, et al. Objectively measured sleep characteristics among early-middle-aged adults: the CARDIA study. Am J Epidemiol 2006; 164: 5-16.

[15] Nishitani N, Sakakibara H. Characteristics of short sleeping time and eating behaviors related to obesity. Obes Res Clin Pract 2012; 6: e103-e109.

[16] Patel SR, Zhu X, Storfer-lsser A, et al. Sleep duration and biomarkers of inflammation. Sleep 2009; 32: 200-4

[17] Utsugi M, Saijo Y, Yoshioka E, et al. Relationships of occupational stress to insomnia and short sleep in Japanese workers. Sleep 2005; 28: 728-35

[18] Knudsen HK, Ducharme LJ, Roman PM. Job stress and poor sleep quality: data from an American sample of full-time workers. Soc Sci Med 2007; 64: 1997-2007.

[19] Nakashima M, Morikawa Y, Sakurai M, et al. Association between long working hours and sleep problems in white-collar workers. J Sleep Res 2011; 20: 110-6.

[20] Nakata A, Haratani T, Takahashi M, et al. Job stress, social support, and prevalence of insomnia in a population of Japanese daytime workers. Soc Sci Med 2004; 59:1719-30.

[21] Nishitani N, Sakakibara H. Job stress factors, stress response, and social support in association with insomnia of Japanese male workers. Ind Health 2010; 48: 178-84. 
[22] Sekiguchi K, Shibui K, Li L, et al. Associations of daily-life related factors and occupations associated with the accumulation of somatic or psychological complaints in the general adult population of Japan. J Kyorin Med Soc 2006; 37: 102-17.

[23] Kato M. Research reports on stress in the workplace and its effects on health, Ministry of Health, Labor and Welfare 'Study on prevention of work-related disease'. Preventive Medicine and Public Health. Tokyo: Tokyo Medical University 2000.

[24] Virtanen M, Ferrie JE, Gimeno D, et al. Long working hours and sleep disturbances: the Whitehall II prospective cohort study. Sleep 2009; 32: 737-45.

[25] Sokejima S, Kagamimori S. Working hours as a risk factor for acute myocardial infarction in Japan: case-control study. BMJ 1998; 317: 775-80.
[26] Nakata A. Work hours, sleep sufficiency, and prevalence of depression among full-time employees: a community-based crosssectional study. J Clin Psychiatry 2011; 72: 605-14.

[27] Amagasa T, Nakayama T, Takahashi Y. Karojisatsu in Japan: characteristics of 22 cases of work-related suicide. J Occup Health 2005; 47: 157-64.

[28] Nakata A. Investigating the associations between work hours, sleep status, and self-reported health among full-time employees. Int J Public Health 2012; 57: 403-11.

[29] Kageyama T, Nishikido N, Kobayashi T, Kawagoe H. Estimated sleep debt and work stress in Japanese white-collar workers. Psychiatry Clin Neurosci 2001; 55: 217-9.

(C) Nishitani et al.; Licensee Bentham Open.

This is an open access article licensed under the terms of the Creative Commons Attribution Non-Commercial License (http://creativecommons.org/licenses/by$\mathrm{nc} / 3.0 /$ ), which permits unrestricted, non-commercial use, distribution and reproduction in any medium, provided the work is properly cited. 